\title{
Correspondence
}

\section{Value of submerged early human sites}

Your articles on human dispersal in the late Pleistocene epoch (Nature 485, 23; 2012) overlook the significance of nowsubmerged archaeological sites on the continental shelf during this period (126,000-11,000 years ago). It is wrong to assume that these were completely destroyed by the sea and that the interpretation of human movements must rely on proxy data, such as DNA or evidence from islands.

More than 3,000 prehistoric sites on the seabed have been found and mapped, and in some cases excavated. They range in age from 500,000 to 5,000 years old, and at locations from the present-day shoreline out to a depth of 130 metres. These sites were extensive, often located on key travel routes and more attractive than arid hinterlands to human settlers.

Marine archaeologists have recovered in-context stone artefacts, animal remains and human fossils from such sites. Some materials, including food remains, organics, bone, DNA and plants, are better preserved underwater than on land.

Questions of early human dispersal will not be resolved until continental shelves are fully investigated - spurred by advances in modern oceanographic technology (see http://splashcos.org).

Nicholas Flemming National Oceanography Centre, Southampton, UK. n.flemming@sheetsheath.co.uk Geoffrey N. Bailey University of York, UK.

Dimitris Sakellariou Hellenic Centre for Marine Research, Athens, Greece.

\section{Two faces of marine ecology research}

The ecology of animal movement is one field that would benefit from sound evaluation of the risks, benefits and ethics of its important research findings (Nature 484, 415 and Nature 484, 432-434; 2012).

Scientists can now track the complex horizontal and vertical movements of a wide range of marine species, including tuna, sharks and turtles. These results reveal biodiversity hotspots and inform conservation policies by providing insight into animal behaviour and ecology. However, they also guide fishing operations towards resource-rich locations putting further strain on both target and by-catch species.

Too many species face severe stock depletion because of intense fishing, pollution and other anthropogenic pressures. The detrimental implications of marine ecological research results must be acknowledged. Juerg Brunnschweiler Swiss Federal Institute of Technology (ETH Zurich), Zurich, Switzerland. juerg@gluecklich.net

\section{Villages project responds to criticism}

Some of your criticisms of child-mortality figures from the Millennium Villages project in Africa are unjustified (Nature 485, 147; 2012).

You question the methods we used to generate mortality estimates, which were based on mothers' recall of the numbers of births and deaths of their children (P. M. Pronyk et al. Lancet http://dx.doi.org/10.1016/ s0140-6736(12)60207-4; 2012).

But this is standard practice, and was approved by the paper's reviewers. To avoid any potential systematic bias, we used the same technique and reporting period for the Millennium and comparison villages.

No "alarm bells" sounded over the mortality rate in the comparison villages. These were closely matched to the Millennium sites, chosen because they were poor, often remote, hunger hotspots. We therefore had no expectation that mortality rates at any of these sites would track national trends.

You wrongly suggest that the costs of the project were not properly reported. Our paper presents costs by site, sector and funding source - providing much more information than in most comparable studies. Detailing intervention costs and spending by partners is a core purpose of the project, executed with scrupulous care.

Our results on the decline in child mortality in the Millennium Villages are statistically significant over time and, in relation to the comparison villages, follow protocol. As you point out, the comparisons made with national trends were not tested for statistical significance, which is why they have been withdrawn (P. Pronyk Lancet http://dx.doi.org/10.1016/S01406736(12)60824-1; 2012).

Since then, the project has been piloting techniques for assessing changes in the under- 5 mortality rate in the Millennium Villages using trained community-health workers to collect detailed, accurate birth and death data. Leading experts on public health will be invited to form an independent committee to review and help strengthen the collection and processing of these data.

Paul Pronyk Center for Global Health and Economic Development, Earth Institute, Columbia University, New York, USA.

ppronyk@ei.columbia.edu

\section{Pitfalls of Romania's ethics council}

Changes to the laws of the Romanian government's National Ethics Council, created in 2004 to control misconduct and plagiarism in scientific research (Nature 485, 289; 2012), have been hailed as a boost to the country's research

reforms. But preventable pitfalls threaten the council's prospects for success.

The council's 11 members have impeccable credentials and have issued bold pronouncements. However, the council has only advisory status and no legal powers. Rather than seeking cross-party consensus on membership, the education minister retains the power to appoint council members, who are therefore vulnerable to accusations of political bias.

The council's powers are further restricted because it has no access to anti-plagiarism software or to comprehensive databases. Members must judge the cases brought to them, some of which could be politically motivated and might affect public perception of the council.

As you point out, the government's new antiplagiarism legislation rules that any academic found guilty of misconduct will lose his or her job. Such sanctions can be retroactive, affecting scientists appointed before the new regulations came into force - a questionable strategy prohibited by most constitutions, including Romania's.

It remains to be seen whether these factors will prevent the ethics council from acting efficiently, asserting its independence and gaining the role it deserves.

Octavian Voiculescu University of Cambridge, UK. ogv20@cam.ac.uk

CONTRIBUTIONS

Correspondence may be submitted to correspondence@nature. com after consulting the author guidelines at http:// go.nature.com/cmchno. Alternatively, readers can comment online on anything published in Nature: www.nature.com/ nature. 